\title{
Factors Influencing the Youths' Interest in Agricultural Entrepreneurship in Sri Lanka
}

\author{
Dhammika. P. Withanage \\ University of Sri Jayewardenepura, Sri Lanka \\ B.W.R Damayanthi \\ University of Sri Jayewardenepura, Sri Lanka
}

\begin{abstract}
Aversion to working in agriculture by the youth, is prima facie evident in the country. The declining interest of the youngsters to work in the agriculture makes a great impact on the future sustainability of this sector. Given this context, the main objective of this research is to explore non-plantation agriculture sector to examine the youth aspirations towards agricultural employment choice in Sri Lanka. Data were collected from a multi stage cluster sample of 400 youth and their parents using a self-administered questionnaire. Descriptive statistics revealed that insufficient income, insufficient lands, limited opportunities, low social acceptance are the driving force of the farmers' reluctance on encouraging their children towards farming. Estimated binary logistic model found that the youth aspirations towards the agricultural entrepreneurship was strongly influenced positively by attitude, acceptance, parental satisfaction on agricultural income, parental income, agro machine ownership, land ownership, expected government support and credit facilities while parental education showed a negative effect. Effective awareness raising campaigns to improve parents and society's attitudes, well-designed training and knowledge enhancing programs to detail the opportunities which secure the trust, address the issues faced by the sector in terms of advancing the technology; marketing and seeking international opportunities, forming of effective young farmers' organizations and empowering them to raise necessary bargaining power, providing necessary facilities such as water conservation/harvesting and irrigation systems, local seed banks and so on are suggestions made by the study.
\end{abstract}

Keywords: Youth aspirations; Employment choice; Agriculture; Farmers' willingness; Sri Lanka

DOI: $10.7176 / \mathrm{DCS} / 9-12-05$

Publication date: December $31^{\text {st }} 2019$

\section{Introduction}

Agriculture creates the backbone of most of the economies, especially in developing countries. Sri Lanka is also blessed with an agricultural history dating back over 2500 years. For our ancestors, agriculture was not just an economic activity but a way of directing and shaping the culture, society and the religion of the nation for centuries. In light of that, Sri Lanka was affectionately called as the Granary of the East. Furthermore, the island's moderate climate throughout the year, fertile soil, two monsoons etc. provided the ideal background for the agricultural activities. Because of that, agricultural sector of Sri Lanka performed as a major force which contributed the national economy, employment and the food security. However, the current contribution of agricultural sector to the GDP is only $7 \%$. Out of that, fisheries sector contributes $1.2 \%$ and the livestock sector accounts around $0.6 \%$ (Central Bank Report, 2018). The productivity and profitability of the yield hamper the growth of the sector, even though Sri Lanka is a tropical land with the potential for cultivation and processing of variety of crops.

In Sri Lanka, 23\% from the total population is youth (National youth Policy, 2014) and there are many factors that make agriculture is not so attractive to young workforce. In developing countries like Sri Lanka, more entrepreneurs tend to be pushed entrepreneurs. i.e. they are highly motivated by the necessity rather than the opportunity (Hessels et al, 2008). Therefore, stepping down of youth from the agricultural entrepreneurship is one of the most emerging issue in the country. The declining interest of the youngsters to work in the agriculture makes a great impact on the future sustainability of this sector. In future, the world population will increase to 10 billion by 2050 . For Sri Lanka, it is needed to increase the food production by $50 \%$ from the current level to feed the population in 2030 in order to save from the hunger (Business Times, 2017).

Therefore, the government plays a major role in promoting the increase of food production, its scale and the productivity by employing the productive labour in the country. In that case, the interest of youngsters to be the next generation farmers should be frosted in agricultural sector. In this regard, out-migration, aversion to working in agriculture and the aging of farmers are serious problems that raise questions about who will work in agriculture in the future. Low incomes and uncertainty of incomes due to vagaries in the weather and other factors have discouraged youth taking up employment in agricultural pursuits (Korale, 2007). Further, underemployment in the sector is burning issue. Over 80 per cent of the rural population depends on agriculture for food as well as employment (CBSL, 2015). Therefore, agriculture and the rural economy play an important role in the lives of many people in rural areas, including young people and will continue to do so into the future. However, even the 
government support is shown to be not enough to motivate people to work in agriculture (Bednarikova et al., 2016). Aversion to working in agriculture, especially by the youth, is prima facie evident in the country. Many young people are reportedly choosing not to pursue livelihoods in agriculture, especially as farmers (Abdullah \& Sulaiman, 2013; IFAD, 2012). If this is the case, there are clear implications for the future of agriculture, especially at a time where the country is faced with many challenges towards improving food security and poverty reduction. Even with a trend of young people migrating to urban centres, agriculture will remain the largest employer in many countries (Bednarikova et al., 2016). But it is too often seen as an 'employment of last resort', avoided by young people, especially by those with secondary and tertiary education. Yet an increasing number of youths remain unemployed and authorities seem to be incapable or unwilling to do what is necessary to provide young people with employment in the agriculture sector (Abdullah \& Sulaiman, 2013). Hence, the question "what do we do to make agriculture attractive to young job-seekers" which has to answered from the youth's point of view is vital for an effective policy formulation, especially, to support more young people to develop agricultural enterprises and view agriculture as a viable career option (IFAD, 2012). Given this context, the main objective of this research is to explore non - plantation agriculture sector to examine the youth aspirations towards agricultural employment choice in Sri Lanka.

\section{Methods}

\subsection{Sample and data}

Research design: this study aims at examining the youth's willingness of choosing agriculture entrepreneurship. Willingness is basically a psychic concept which is expected to be dependent on a person's socioeconomic, political as well as psychological reasons. Hence, primarily this an explanatory research which adopt both descriptive and correlational types and further, the study is non experimental.

Sampling and data collection: Sampling for the main questionnaire survey was done under multi stage cluster sampling method. First two divisional secretariats from each administrative district, Badulla and Monaragala, were randomly selected and then four Grama Niladari (GN) divisions from each DS were selected. Selected GN divisions from Badulla district were Bogahakumbura, Kandakatiya, Baddekumbura and Bandarawela-East while Wellawaya, Kiriibbanwewa, Buduruwagala, Sewanagala were selected from Monaragala district. Then a random sample of farmer households and then a young from each household was selected from a randomly chosen village from each GN. Altogether a sample of 400 subjects from both districts was selected and the questionnaire was administered.

Data collection and preparation: The main data collection tool was questionnaire in different forms designed to gather required data from the youth. Main data collection method was questionnaire survey which was conducted in 2018 using the interview method. Besides, as the preliminary survey and collecting of qualitative information were done conducting series of focus group interviews in each district with farmers, farmer associations and with the youth.

The contents of the questionnaire were as follows: (a). general characteristics of rural households, including age, race, region etc, educational status of householder, the number of family members the details; (b). Dwelling characteristics, assets endowment, monthly household expenditure and income, etc.; (c). data on production of vegetables/rice and agricultural machines; (d). youth employment aspirations and parental willingness

Data preparation and validation: As usual in any social science research, the original data collections for this study were done in different forms: scale and nominal. However, they were meaningfully recorded so that the requirements of the statistical models are met. Data cleansing and validation is a vital part in the research process to ensure reproducibility of research findings. Entered data were primarily screened for wild codes, inconsistencies, outliers and influential cases. Using data cleaning facilities provided by SPSS 22.0 outliers were identified and managed so that the statistical models can be estimated with minimum data distortions. For the ratio variables true outliers were replaced by the average while some of the extreme outliers were deleted. In case of design variables, some of the wild codes were replaced by the most probable codes identified through cross-checking questions. However, deletion method was used with special attention because it may distort the actual structure of the data (Field, 2009).

\subsection{Empirical model}

The main objective of the current study is to investigate the determinants of youth's willingness of agricultural entrepreneurship. Thus, the dependent variable for the current study is youth's willingness of engaging agricultural entrepreneurial works. Accordingly, dichotomous dependent variable takes value 1 if a youngster likes to be an agricultural entrepreneur and 0 otherwise. Standard binomial logistic regression is the form regression that can be used when the dependent is dichotomy and the independents are of any type: continuous, categorical. Logistic regression can be used to predict the binary outcome variable on the basis of independents, to determine the variation of the dependent variable that is explained by the independents as well as to identify the relative importance of individual predictors. Hence, the use of logistic regression was appealing for the current study. The 
basic form of the model can be shown as,

$$
y_{i}=\sum_{j=0}^{k} X_{i j} \beta_{j}+\varepsilon_{i}
$$

Where y denotes binary dependent variable, $\beta$ is vector of parameters and the error term $\varepsilon$ which has zero mean and logistic distribution. If $P_{i}$ is the probability that a young person chooses agricultural entrepreneurship, Bernoulli variable which depends on the vector of predictors $X$,

$$
P_{i}(X)=\frac{e^{\alpha+\beta X}}{1+e^{\alpha+\beta X}}
$$

In this regard, the logistic regression model consisting of $\mathrm{n}$ independent variables can be described as:

$$
\text { logit }(P)=\beta_{0}+\beta_{1} X_{1}+\beta_{2} X_{2}+\cdots+\beta_{n} X_{n}
$$

This shows the application of maximum likelihood estimation after transforming the dependent variable into logit variable: natural log of the odds of the dependent occurring or not. The left side of the equation denotes the natural logarithm of likelihood which corresponds to the ratio of the occurrence and non-occurrence of events. Hence,

$$
\operatorname{logit}(P)=\ln \left(\frac{P\left(Y_{1}\right)}{P\left(Y_{0}\right)}\right)=\beta_{0}+\beta_{1} X_{1}+\beta_{2} X_{2}+\cdots+\beta_{n} X_{n}
$$

Where $Y_{1}$ means the young is willing to engage in agricultural entrepreneurship, $Y_{0}$ otherwise or the young is not willing to proceed as an agricultural entrepreneur. The left side of the equation denotes the natural logarithm of likelihood which corresponds to the ratio of the occurrence and non-occurrence of events. The independent variables $X_{1}$ to $X_{n}$ represent independent variables or the factors affecting the youth willingness of engaging agricultural entrepreneurship.

Variables: Dependent variable: Youth's willingness of agricultural entrepreneurship is dummy coded binary variable which is assigned a value 1 if the youngster is willing to be an agricultural entrepreneur and 0 otherwise. Independent variables are Attitude, Acceptance, Knowledge, Parental income, Parental education Agri machines at home, Expected government support, Credit facilities, Land ownership, Parental satisfaction on agri income.

\section{Results}

\subsection{Descriptive analysis}

As shown in Table 1, 76 percent of the sampled farmers are not willing to move their children into agricultural sector as farmers. Only 16.5 of the respondents like to promote farming for the children. Once this choice is examined with the level of income, as shown in Figure 1, the majority who likes to keep their children engage in farming are from the highest quartile.

Table 1: Farmer's perception on moving their children into farming

\begin{tabular}{lrrrr}
\hline Option & Frequency & Percent & Valid \% & Cumulative \% \\
\hline Like & 46 & 5.2 & 6.5 & 6.6 \\
No dislike & 118 & 13.2 & 16.9 & 23.4 \\
Dislike & 179 & 20.1 & 25.6 & 49.0 \\
Strongly dislike & 357 & 40.1 & 51.0 & 100.0 \\
Total & 700 & 78.6 & 100.0 & \\
System missing & 191 & 21.4 & & \\
Total & 891 & 100.0 & & \\
\hline
\end{tabular}

Source: Author's calculations based on sample data 
Figure 1: Income quartile distribution of agri choice for children

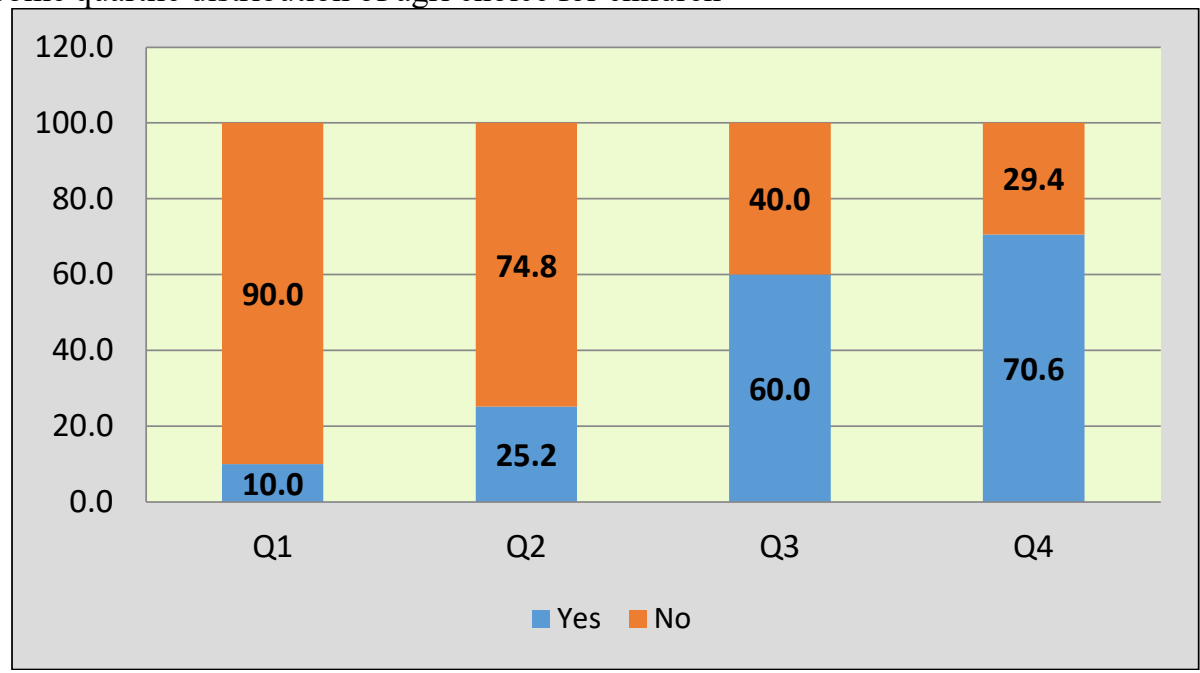

Source: Author's calculations based on sample data

It is informative and worthwhile in comparing this willingness with the human capital variables like education. Once the farming choice over the level of education is taken, primary or junior secondary level educators show their reluctance of employing the children as farmers while middle level educators like to keep agricultural activities as a source of income. Having identified the opportunities, they like to explore the sector but as a supportive income. People who have completed higher education like to keep the children away from agriculture (ref Table 2).

Table 2: Farmers education level and their perception on children's Agri choice

\begin{tabular}{|c|c|c|c|}
\hline \multirow[t]{2}{*}{ Education level } & \multicolumn{3}{|c|}{ Option } \\
\hline & Yes & & \\
\hline Grade 5 or below & & 22.5 & 72.5 \\
\hline Grade 6 to $\mathrm{O} / \mathrm{L}$ & & 15.6 & 80.4 \\
\hline $\mathrm{A} / \mathrm{L}$ & & 69.1 & 30.9 \\
\hline $\mathrm{A} / \mathrm{L}$ pass & & 82.3 & 17.7 \\
\hline Graduate & & 90.3 & 7.7 \\
\hline
\end{tabular}

Source: Author's calculations based on sample data

Table 3 depicts the reasons behind farmers' reluctance of employing their children in agricultural sector as farmers. Insufficient income is the driving force of the reluctance while 32.3 percent of the farmers stated that they have no enough land to occupy their children as full time farmers. The size of the farming land is gradually decreasing from generation to generation and now it is a residential land plot which is not large enough for cultivation. Further, a considerable proportion of sampled farmers believe that there are very limited opportunities agricultural sector to get uplifted.

It was found that the majority of the farmers believe that the opportunities available in agricultural sector is very limited. This implies that farmers' knowledge has not been updated and improved. The need of well-designed training and knowledge enhancing programs are well acknowledged. Especially, introducing and improving agrobased industries, initiating commercial agriculture and preparing the sector for the foreign market would be essential. Local universities can contribute on this matter. Agricultural faculties can address the issues faced in advancing the technology, marketing and seeking international opportunities.

Table 3: Reasons behind farmer's reluctance

\begin{tabular}{lccc}
\hline & Reason & 1st reason & Cited \\
\hline Not profitable & 7.4 & 20 \\
Income not sufficient & 16.8 & 34.6 \\
No opportunities & 13.2 & 30.8 \\
Gvt support is not sufficient & 5.2 & 8.2 \\
indebtedness & 19.2 & 20.3 \\
Land is not sufficient & 14.5 & 32.3 \\
\hline
\end{tabular}

Source: Author's calculations based on sample data 
Table 4: Demographic and socioeconomic profile of the youth

\begin{tabular}{|c|c|c|c|}
\hline Variable & Description & Frequency $\quad N=384$ & $\%$ \\
\hline \multirow[t]{3}{*}{ Age } & $15-17$ & 82 & 21.3 \\
\hline & $18-24$ & 186 & 48.4 \\
\hline & $25-30$ & 116 & 30.2 \\
\hline \multirow[t]{2}{*}{ Gender } & Male & 343 & 89.3 \\
\hline & & 41 & 10.6 \\
\hline \multirow[t]{3}{*}{ Ethnicity } & Sinhalese & 302 & 78.6 \\
\hline & Muslim & 80 & 20.8 \\
\hline & Other & 4 & 1.0 \\
\hline \multirow[t]{3}{*}{ Marital status } & Single & 283 & 78.6 \\
\hline & Married & 92 & 23.9 \\
\hline & Other & 9 & 2.3 \\
\hline \multirow[t]{3}{*}{ Employment status } & Employed & 170 & 44.2 \\
\hline & Unemployed & 112 & 29.1 \\
\hline & Student & 102 & 26.5 \\
\hline \multirow[t]{6}{*}{ Education } & $\mathrm{O} / \mathrm{L}$ or less & 70 & 18.2 \\
\hline & $\mathrm{A} / \mathrm{L}$ sat & 110 & 28.6 \\
\hline & $\mathrm{A} / \mathrm{L}$ Pass & 122 & 31.7 \\
\hline & Diploma & 62 & 16.1 \\
\hline & Graduate & 18 & 4.6 \\
\hline & Higher & 2 & 0.5 \\
\hline
\end{tabular}

Source: Author's calculations based on sample data

Table 4 shows the basic demography of the sampled youth. The respondents who are between $15-17$ years old formed 21.3 percent while the majority (48 percent) lies between $18-24$ years of age. When gender distribution of the sample is taken, vast majority (89.3) is male. In terms of ethnicity, 78.6 are Sinhalese, 20.8 are Muslims and the rest 4 percent is from other races. Once the marital status category is taken, 78.6 percent are single, 23.9 percent are married while 2.3 percent are from other categories.

The respondents are classified into four categories based on their educational background. The first group is $\mathrm{O} / \mathrm{L}$ or less educators that comprises 18 percent of the sample. A/L sat percentage is about 29 percent while $\mathrm{A} / \mathrm{L}$ pass make up the biggest percentage (31.7). 16 percent of the sampled youth are diploma holders and those with degree qualification make up about 4.6 percent of the sample. The forth group which includes Masters or higher degree holders is only 0.5 percent. When employment status is taken, the majority, 44.2 percent, are employed in government or private institutions on permanent or temporary/contact basis. About 30 percent is unemployed.

Table 5: Mean values of main composite variables across youth willingness

\begin{tabular}{llll}
\hline & Variable & \multicolumn{2}{c}{ Willingness : agro entrepreneur } \\
\cline { 2 - 3 } & & Yes & No \\
\hline Attitude & 2.1 & 1.4 \\
Acceptance & 2.4 & 1.3 \\
Knowledge & 3.1 & 3.0 \\
\hline
\end{tabular}

Source: Author's calculations based on sample data

As shown in Table 5 the mean of "attitude" for the young who are willing agricultural entrepreneurship is 2.1 from a five of Likert-scale while it is 1.4 for the unwilling group. Mean value for acceptance is 2.4 and for knowledge is 3.1 for this group while these values are 1.3 and 3.0 respectively for the other group. Results of this study demonstrate that perceptions on all three concepts are comparatively low as a whole. The values are much lower for the youth who are unwilling to stay as agro entrepreneurs. 
Table 6: Reasons behind unwillingness to become farmer

\begin{tabular}{lcc} 
& \multicolumn{2}{c}{ Percentage } \\
Item & 1st rank & Cited \\
\cline { 2 - 3 } Parents dislike & 34.2 & 65.1 \\
No sufficient land & 45.2 & 56.1 \\
Agri income is not sufficient & 76.2 & 80.1 \\
No stable income & 78.2 & 85.0 \\
No sufficient gvt support & 24.1 & 30.3 \\
No price stability & 79.1 & 88.2 \\
Climate conditions & 58.9 & 72.1 \\
Water problem & 62.0 & 65.2 \\
No social acceptance & 67.3 & 75.4 \\
Knowledge is not sufficient & 23.1 & 31.2 \\
Very hard job & 56.8 & 67.3 \\
\hline
\end{tabular}

Source: Author's calculations based on sample data

As depicted in Table 6, the majority of the youngest are unwilling to do farming due to income related matters. For 88 percent, the first reason of not entering into agricultural sector as a farmer or small entrepreneur is instability of the income aroused from unstable and low price. Consequently, insufficiency of income has been mentioned as one of the important matters. Before going to climate related factors, it is shown that social acceptance is also a big factor. Further, agricultural activities are very hard for more than half of the sampled young.

\subsection{Results of Binary logistic model for youth aspirations toward agricultural entrepreneurship}

Table 7: Model fit statistics of binary logistic model

\begin{tabular}{|c|c|c|}
\hline \multirow[b]{2}{*}{ Indicator } & \multicolumn{2}{|l|}{ Models } \\
\hline & $1^{\mathrm{a}}$ & $2^{b}$ \\
\hline \multicolumn{3}{|l|}{ Pseudo $\mathrm{R}^{2}$} \\
\hline Cox \& Snell $\mathrm{R}^{2}$ & $0 . .332$ & 0.450 \\
\hline Negelkerke $\mathrm{R}^{2}$ & 0.450 & 0.522 \\
\hline \multicolumn{3}{|l|}{ Chi Square } \\
\hline Block & $45.820 *$ & $117.31 *$ \\
\hline Model & $83.797 *$ & $139.57 *$ \\
\hline $\mathrm{H}-\mathrm{L}$ & $4.7^{\mathrm{ns}}$ & 21.311 \\
\hline Predictors & 6 & 14 \\
\hline Valid Cases & 202 & 202 \\
\hline $\operatorname{Max} \operatorname{SE}(\beta)$ & 0.781 & 0.959 \\
\hline \multicolumn{3}{|l|}{ Classification } \\
\hline Model & 78.7 & 94.7 \\
\hline
\end{tabular}

${ }^{\mathrm{a}}$ model step 1 without predictors

${ }^{\mathrm{b}}$ model with all predictors

$* \mathrm{p}<.025$

As indicated in Table 7, the minimum ratio of valid cases to independent variables for binary logistic regression is (10 to 1$)$ met for the estimated model in the study. There are 202 valid cases for 14 independent variables for the final model. Overall significance of the model is based on the statistical significance of the model chi-square the model chi-square is statistically significant at 1 percent level of significance $(\mathrm{p}=.000<0.01)$. Further, classification accuracy for the null model was 69 percent which gas been significantly improved to 78.7 for the model with control variables while it is further improved to 94.7 with the inclusion of control variables into the model. Furthermore, there are no improbable standard errors showing numerical problems. The maximum SE value recorded in the final model was 1.147 . Hence the estimated binary logistic model meets required validity allowing the model to be interpreted. 
Table 8: Logistic regression results: youth's willingness toward agricultural entrepreneur

\begin{tabular}{lccc}
\hline Variable & $\beta$ & S.E. & $\operatorname{Exp}(\beta)$ \\
\hline Attitude & $1.3^{* *}$ & 0.51 & 3.69 \\
Acceptance & $1.2^{* *}$ & 0.44 & 3.10 \\
Knowledge & 0.56 & 1.3 & 0.18 \\
Parental income & $0.23^{*}$ & 0.11 & 1.26 \\
Parental education & $-0.48^{* *}$ & 0.10 & 0.21 \\
Agri machines at home & $0.18^{*}$ & 0.05 & 1.19 \\
Expected government support & $0.07^{*}$ & 0.01 & 1.07 \\
Credit facilities & $0.15^{* *}$ & 0.07 & 1.05 \\
Land ownership & $1.16^{* *}$ & 0.46 & 3.19 \\
Parental satisfaction on agri income & $1.37^{* *}$ & 0.59 & 5.67 \\
\hline
\end{tabular}
$* * \mathrm{p}<0.05 ; * \mathrm{p}<0.1$

Table 8 presents the results of the logistic model, where the dependent variable takes 1 when a young is willing to be an agricultural entrepreneur and 0 if unwilling. The coefficients reported in first column are the marginal effects that have been derived controlling for other variables. Once the model fit indices are concerned, the model $\chi^{2}$ value was reported as $143.9 ; \mathrm{p}<.001$ while pseudo $\mathrm{R}$ square values are reasonably good and comparable recording Cox \& Snell as 0.302 and 0.312 for Nagelkerke. Hosmer-Lemeshow $\chi 2$ value of 119.1 is insignificant at 5 percent level of significance showing that the model fits to the data well.

Youth respondent's perception on agricultural sector entrepreneurship in terms of attitudes, acceptance and the knowledge were examined first. As shown is Table 33, attitude and the acceptance are positive and significant at conventional levels recording the beta values as 1.3 and 1.2 respectively. Knowledge is not significant in explaining the intended choice. Parental income is positive and statistically significant at 5 percent level of significance while parental education level is negatively significant. Increase in this factor decrease the odds of being an entrepreneur in the agri sector by about 0.21 fold. Whether respondent have an agricultural machinery included is important to consider effects of existing capital. The respective beta coefficient. 0.18 , is positive and significant at 10 percent level of significance. Increase of capital would increase the probability of being an entrepreneur by 1.19 times. Further, whether respondent expect a substantial support from the government is hardly significant recording very small effect size. Respondent's expectations on credit facilities is significant recording beta coefficient 0.15 . Land ownership and parental satisfaction on agro income are strong and positively significant at 5 percent level of significance. The youth who own a land are more likely to be entrepreneur that those who do not own.

\section{Discussion and conclusions}

Aversion to working in agriculture by the youth, is prima facie evident in the country. The declining interest of the youngsters to work in the agriculture makes a great impact on the future sustainability of this sector. Given this context, the main objective of this research is to explore non-plantation agriculture sector to examine the youth aspirations towards agricultural employment choice in Sri Lanka.

It was found that the youth aspirations towards the agricultural entrepreneurship is strongly influenced positively by attitude, acceptance, parental satisfaction on agricultural income, parental income, agro machine ownership, land ownership, expected government support and credit facilities while parental education showed a negative effect.

Insufficient income, insufficient lands, limited opportunities, low social acceptance are the driving force of the farmers' reluctance on encouraging their children towards farming. It was found that the majority of the farmers believe that the opportunities available in agricultural sector is very limited. This implies that farmers' knowledge has not been updated and improved. The need of well-designed training and knowledge enhancing programs are well acknowledged. Especially, introducing and improving agro-based industries, initiating commercial agriculture and preparing the sector for the foreign market would be essential. Local universities can contribute on this matter. Agricultural faculties can address the issues faced in advancing the technology, marketing and seeking international opportunities.

As it was found, parental satisfaction on agricultural income is most influential factor that determine the youths' entrance to the sector. As revealed by the descriptive statistics, the majority of the farmers are dissatisfied or less satisfied with income they received. Taken together, unless the actions towards increasing farmer income are not taken, this factor may work as a damping factor to remove the youth from the sector. Thus, it is very advisable in increasing faming income in a sustainable way. As it was found farmers' burning issue is price decrease in the season and the volatile price which crate them income instability. Expansion of post harvesting technologies to preserve the products and directing them to foreign market will be helpful in this regard. If the youth see that their parents are prosperous and experience a good life with the agricultural income they received, they tend to enter into the sector. Parents may encourage them. Further, it may support the youth to think that the 
opportunities available in the agricultural sector is good to move their life ahead. Effective awareness raising campaigns are also critical in this regard.

Social attitude towards agricultural sector is found to be very influential in setting young mind towards agricultural entrepreneurship. If the society see the agricultural entrepreneurs as successful businessmen and they serve they nation, the young tend to choose the sector to invest. They would not choose to occupy as three-wheeler drivers. The existing scenario encourage the youth to earn money in an easy way without much physical effort. Farmers or agricultural entrepreneurs are not superior to three-wheeler (TW) drivers. While the framers wasting time and becoming frustrated in front of powerful intermediators, TW drivers earn at their own, more freely and sustainably. Change in this situation should be forefront of development agenda in the country. Securing domestic agriculture through a sound national policy is essential and one of the urgent need for Sri Lanka. The other way of overcoming these power asymmetries is access to market information. When this information is available, better decisions are made on future crops and on where and when to buy and sell goods. Further, forming of effective young farmers' organizations that would construct necessary bargaining power to interact on equal terms with other market actors. Through these organizations will help to take advantage of economies of scale when selling their goods.

Land ownership is reported to be explaining the youth participation strongly. Majority of the respondents stated that they were not practicing due to land related matters. It was identified as one of the main factors that refrains them from starting a farming activity. Inheritance is still the most common system to obtain land in most developing countries and so in Sri Lanka. Land is usually passed on from father to son(s). Life expectancy is increasing and consequently, rural youth often have to wait many years before inheriting their share of the family land. Further, since youth are working as family members, they are getting no or little income. Youth (especially those with many siblings) end up inheriting just a very small piece. Therefore, Youth often inherit small plots of land and lack access to finance to buy an enough land. Actions must be taken to overcome these constraints. Cooperative farming can be tested as it has been a successful role model to Asia. Further, governments can take necessary steps to use arable government land for agricultural purpose. These lands can be fairly distributed among the young. In order to make these programs more successful, government should act as an effective agent to the youth by providing necessary facilities. Water conservation/harvesting and irrigation systems, local seed banks and so on.

Social acceptance was one of the triggering factors of youths' decision to enter agricultural sector as entrepreneurs. When the farmers are not properly accepted as a key contributor of the economy and when they are not respected, negative perceptions would be aroused. This leads to create low self-efficacy. It was revealed that perception and social status act as barriers to youth pursuing careers in agriculture while it was aggravated by the lack of information. The low self-esteem crated by low social acceptance increases youths' negative perception about agriculture, leads to reduce agricultural sector participation.

Parental income is founded to be an encouraging factor for the youth to find their place in agricultural sector. When the parents have sufficient income beyond the basic level, the cost arising at the beginning stages can be bearded. Further, it was revealed that the young who have agricultural capital at home tend to be involve with farming. This implies the need of having sufficient initial capital as well as sufficient income to keep the business developed. In this regard, the young people should be trained and given technical assistance in setting up their farming activities using new technologies. Youth often pick up new technologies more easily. Therefore, income diversification through agro-tourism, culinary tourism, herbal preparations and cosmetics production etc could be introduced for young farmers who are very creative in exploiting new opportunities and thereby stabilizing agricultural income. Furthermore, including of marketing of agricultural products, agricultural technologies and financial management in agriculture in educational curricula even from the secondary school onwards would be very helpful in making the youth motivated into the sector.

\section{References}

Ambad, S. N. A., \& Damit, D. H. D. A. (2016). Determinants of entrepreneurial intention among undergraduate students in Malaysia. Procedia Economics and Finance, 37, 108-114.

Chan, C., Sipes, B. S., \& Lee, T. (Eds.). (2017). Enabling Agri-entrepreneurship and Innovation: Empirical Evidence and Solutions for Conflict Regions and Transitioning Economies. CABI.

Kising'u, J. M. (2016). Factors Influencing Youth Participation in Agricultural Value Chain Projects In Kenya: A Case of Kathiani Sub-County, Machakos County, Kenya. Nairobi, Kenya: University of Nairobi.

Mohamed, Z., Rezai, G., Nasir Shamsudin, M., \& Mu'az Mahmud, M. (2012). Enhancing young graduates' intention towards entrepreneurship development in Malaysia. Education+ Training, 54(7), 605-618.

Pelzom, T., \& Katel, O. (2018). Youth Perception of Agriculture and potential for employment in the context of rural development in Bhutan. Development, Environment and Foresight, 3(2), 92-106.

Ridha, R. N., \& Wahyu, B. P. (2017). Entrepreneurship intention in agricultural sector of young generation in Indonesia. Asia pacific journal of innovation and entrepreneurship, 11(1), 76-89. 
Saadi, H., Mirzayi, K., \& Movahedi, R. (2016). Barriers of the development of web-based training in agricultural higher education system in Iran: A case study of Hamadan Bu Ali Sina University, Iran. Education and Information Technologies, 21(1), 53-70.

Samah, B. A., D'Silva, J. L., Shaffril, H. A. M., \& Uli, J. (2010). Attitude towards contract farming among malaysian agriculture learning institution students. American Journal of Economics and Business Administration, 2(3), 266.

Sher, A., Adil, S. A., Mushtaq, K., Ali, A., \& Hussain, M. (2017). An investigation of entrepreneurial intentions of agricultural students. Pak. J. Agri. Sci, 54(4), 943-947.

Smith, R., McElwee, G., \& Somerville, P. (2017). Illegal diversification strategies in the farming community from a UK perspective. Journal of Rural Studies, 53, 122-131.

van der Zwan, P., Thurik, R., Verheul, I., \& Hessels, J. (2016). Factors influencing the entrepreneurial engagement of opportunity and necessity entrepreneurs. Eurasian Business Review, 6(3), 273-295.

Yusoff, A., Ahmad, N., \& Halim, H. (2015). Promoting Agropreneurship among Gen Y: An Integration of Individual, Institutional and Social Level Factors. Australian Journal of Basic and Applied Sciences, 9(14), 74-86. 